\title{
ANALISIS DIVERSIFIKASI PENDAPATAN RUMAH TANGGA PETANI
}

\author{
Desy Cahyaning Utami* \\ *Dosen Fakultas Pertanian Universitas Yudharta Pasuruan \\ Imail: $\underline{\text { d2.decy@gmail.com }}$
}

\begin{abstract}
The purpose of this study is to,(1) To analyze the level of diversification of farm household income. (2) Analyze the factors that influence the allocation of non-agricultural employment in the sector. (3) Analyze the factors that affect employment opportunities in nonagricultural sector.(4) Analyzing the distribution of farm household income. (5) Analyzing the impact of policies increased by $10 \%$ of land area, the improvement of education head of household by $10 \%$, non-farm income increased by $20 \%$, increase in total non-farm time allocation by $20 \%$, and decreased total time allocation of farm by $15 \%$. The results obtained from the study are as follows: 1. The average household income of farmers in Patuk Baran derived from non-farm activities is much higher than from farming activities, amounting to $\mathrm{Rp}$ 7,010,566 for an average farm income per year and $\$ 13,116,220$ for an average income of non farm per year. 2. Factors that significantly affect income diversification seen from the allocation of work in the agricultural sector is the head of household education, land area and age of head of household. 3. Factors that affect the employment opportunities in agriculture, of labor activity in trade is the total time allocation of farm and labor force in the family. To work activities are broad areas of service and age of head of family land. While on work activities remittance is head of the family and education on the activities of field workers are working in the family labor force, education head of household, land area and consumption. 4. Based on the gini index value of 0.4079 which is still far from one and the Lorenz curve that is close to $45^{\circ}$ line and not too convex, then the distribution of income in Hamlet Patuk Baran evenly. 5. The impact of increased education head of household by $10 \%$, causing an increase in non-farm income, ie income trading, services, and labor as well as lower farm receipts. Increased nonfarm income by $20 \%$ impact on increasing trade and services revenue, this policy aims to increase the amount of employment or new employment opportunities in rural areas. While the impact of increasing the total time allocation of non-farm non-agricultural sector led to rising incomes Last is the impact of the decline in total time of farming led to declining farm revenues.
\end{abstract}

Key Words: Income Diversification, Household, Gini index

\section{PENDAHULUAN}

Pada rumah tangga pedesaan sering kita beranggapan bahwa sumber utama pendapatan masyarakat berasal dari lahan pertanian. Dimana akan dikaitkan luas tanah yang dimiliki dengan besarnya pendapatan rumah tangga petani. Masyarakat masih beranggapan bahwa apabila tanah yang dimiliki oleh petani luas, maka besar pulalah pendapatan yang diterima dalam keluarganya. Pada saat sekarang ini kenyataan menunjukkan bahwa pendapatan keluarga tidak lagi sepenuhnya tergantung kepada tanah yang dimiliki sebagai indikator pendapatan utama rumah tangga. Usaha pertanian baik di pedesaan maupun di perkotaan saat sekarang ini sudah tidak begitu dominan dan tidak memberikan sumbangan yang besar lagi bagi pendapatan rumah tangga di 
pedesaan. Diversifikasi pendapatan sudah banyak dilakukan oleh masyarakat pedesaan. Menurut beberapa penelitian yang antara lain dilakukan oleh Aart Schrevel di daerah Cidurian Jawa Barat bahwa sebagian besar rumah tangga di daerah ini $(80 \%)$ memperoleh pendapatannya berasal dari kegiatan di luar usahatani. Hal di atas disebabkan mayoritas rumah tangga pedesaan khususnya yang tidak atau memiliki tanah yang sempit, kegiatan sekitar usaha tani merupakan keharusan (mungkin demikian sejak dahulu), sedangkan bagi rumah tangga yang lain kegiatan usaha tani dapat merupakan jalan menambah tingkat subsistensi.

Diversifikasi pendapatan sering dikaitkan dengan upaya penanggulangan risiko, kesempatan dan ketidakpastian pendapatan. Ditingkat rumah tangga, diversifikasi melalui penganekaragaman usaha dan pemanfaatan aset, selain bertujuan untuk mencari nilai tambah kapital juga untuk mengurangi instabilitas pendapatan rumah tangga (Dercon, 2002).

Diversifikasi dapat dilakukan di sektor pertanian, non pertanian, maupun keduanya. Keragaman lingkungan sebagai faktor pendorong dan penarik rumah tangga melakukan diversifikasi pendapatan. Faktor utama atau alasan rumah tangga petani melakukan diversifikasi pendapatan adalah semakin terbatasnya lahan pertanian yang ada, hal ini menyebabkan petani tidak dapat memaksimalkan produksi pertaniannya sehingga penerimaan dari sektor usahatani tidak maksimal dan tidak dapat mencukupi kebutuhan hidupnya. Hal inilah yang menyebabkan rumah tangga petani harus melakukan berbagai aktivitas usaha yang dapat menghasilkan suatu pendapatan guna mempertahankan kelangsungan hidupnya. Faktor sosial, budaya, dan ekonomi ini juga menyebabkan perbedaan diversifikasi usaha dari petani. Selain itu adanya faktor kendala dari diversifikasi pendapatan sendiri adalah faktor keterampilan atau keahlian yang dimiliki seseorang.

Tujuan Penelitian dari penelitian ini adalah (1) Menganalisis tingkat diversifikasi pendapatan rumah tangga petani. (2) Menganalisis faktor-faktor yang mempengaruhi alokasi kerja di sektor non pertanian. (3) Menganalisis faktor-faktor yang mempengaruhi peluang kerja di sektor non pertanian. (4) Menganalisis distribusi pendapatan rumah tangga petani. (5) Menganalisis dampak kebijakan peningkatan pendidikan kepala keluarga sebesar $10 \%$, peningkatan pendapatan non usahatani sebesar $20 \%$, peningkatan total alokasi waktu non usahatani sebesar $20 \%$, dan penurunan total alokasi waktu usahatani sebesar $15 \%$ terhadap pendapatan non usahatani.

\section{METODE ANALISIS DATA}

Dalam penelitian ini, perumusan model mencakup model penerimaan usahatani, model biaya usahatani, model pendapatan usahatani, model biaya tenaga 
kerja usahatani, model tenaga kerja non usahatani, model pendapatan non usahatani, model pendapatan total rumah tangga petani, dan model konsumsi rumah tangga petani. Agar tujuan penelitian sesuai dengan yang ditentukan, maka model dispesifikasi dalam bentuk persamaan simultan yang yang terdiri dari empat belas persamaan struktural dan enam persamaan identitas.

Model fungsi struktural dan fungsi identitas dalam model ekonomi rumah tangga dapat diformulasikan dalam persamaan berikut :

1. Model Penerimaan Usahatani

PNUT $=\mathrm{a} 0+\mathrm{a} 1 \mathrm{BB}+\mathrm{a} 2 \mathrm{BP}+\mathrm{a} 3$ $\mathrm{BPS}+\mathrm{a} 4 \mathrm{BTKUT}+\mathrm{U} 1$

2. Model Biaya Usahatani $\mathrm{BUT}=\mathrm{BB}+\mathrm{BP}+\mathrm{BPS}+$ BTKUT.

3. Model Pendapatan Usahatani

PNDUT $=$ PNUT - BUT

4. Model Biaya Tenaga Kerja Usahatani BTKUT $=\mathrm{b} 0+\mathrm{b} 1 \mathrm{TAWUT}+\mathrm{b} 2$ TAWNUT + b3 AKK + b4 PNDK + b5 $\mathrm{LLN}+\mathrm{b} 6 \mathrm{UMR}+\mathrm{U} 2$

5. Model Tenaga Kerja Non Usahatani

TKDG $=\mathrm{c} 0+\mathrm{c} 1$ TAWUT $+\mathrm{c} 2$ $\mathrm{AKK}+\mathrm{c} 3 \mathrm{PNDK}+\mathrm{c} 4 \mathrm{LLN}+\mathrm{c} 5 \mathrm{UMR}$ $+\mathrm{c} 6 \mathrm{KSM}+\mathrm{U} 3$

TKJS $=\mathrm{d} 0+\mathrm{d} 1$ TAWUT $+\mathrm{d} 2$ $\mathrm{AKK}+\mathrm{d} 3$ PNDK + d4 LLN + d5 UMR $+\mathrm{d} 6 \mathrm{KSM}+\mathrm{U} 4$
TKRMT $=\mathrm{e} 0+\mathrm{e} 1 \mathrm{TAWUT}+\mathrm{e} 2$ $\mathrm{AKK}+\mathrm{e} 3 \mathrm{PNDK}+\mathrm{e} 4 \mathrm{LLN}+\mathrm{e} 5 \mathrm{UMR}$ $+\mathrm{e} 6 \mathrm{KSM}+\mathrm{U} 5$.

TKBR $=\mathrm{f0}+\mathrm{f} 1$ TAWUT $+\mathrm{f} 2$ $A K K+f 3 P N D K+f 4 L L N+f 5 U M R+$ f6 KSM + U6.

TKNUT $=$ TKDG + TKJS + TKRMT + TKBR

6. Model Pendapatan Non Usahatani PNDDG $=\mathrm{g} 0+\mathrm{g} 1 \mathrm{TAWUT}+\mathrm{g} 2$ $\mathrm{AKK}+\mathrm{g} 3 \mathrm{PNDK}+\mathrm{g} 4 \mathrm{LLN}+\mathrm{g} 5 \mathrm{UMR}$ + g6 KSM + U7

PNDJS $=\mathrm{h} 0+\mathrm{h} 1$ TAWUT $+\mathrm{h} 2$ $\mathrm{AKK}+\mathrm{h} 3 \mathrm{PNDK}+\mathrm{h} 4 \mathrm{LLN}+\mathrm{h} 5 \mathrm{UMR}$ $+\mathrm{h} 6 \mathrm{KSM}+\mathrm{U} 8$

PNDRMT $=\mathrm{i} 0+\mathrm{i} 1 \mathrm{TAWUT}+\mathrm{i} 2$ AKK + i3 PNDK + i4 LLN + i5 UMR + $\mathrm{i} 6 \mathrm{KSM}+\mathrm{U} 9$

PNDBR $=\mathrm{j} 0+\mathrm{j} 1$ TAWUT $+\mathrm{j} 2$ $A K K+j 3 P N D K+j 4 L L N+j 5 U M R+$ j6 KSM + U 10

PNDNUT $=$ PNDDG + PNDJS + PNDRMT + PNDBR

7. Model Pendapatan Total Rumah Tangga

PNDTOT $=\quad$ PNDUT
PNDNUT $\ldots \ldots \ldots \ldots \ldots \ldots \ldots \ldots \ldots \ldots \ldots \ldots \ldots \ldots \ldots \ldots \ldots \ldots \ldots \ldots$

8. Model Konsumsi Rumah Tangga

$\mathrm{KSM}=\mathrm{KSMP}+\mathrm{KSMNP} . .(16)$
$\mathrm{KSMP}=\mathrm{k} 0+\mathrm{k} 1 \mathrm{BKB}+\mathrm{k} 2 \mathrm{BKJ}+$
$\mathrm{k} 3 \mathrm{BKSG}+\mathrm{k} 4 \mathrm{BKS}+\mathrm{k} 5 \mathrm{BKD}+\mathrm{k} 6$
$\mathrm{BKG}+\mathrm{k} 7 \mathrm{BKA}+\mathrm{k} 8 \mathrm{BKR}+\mathrm{k} 9 \mathrm{BKT}+$
$\mathrm{k} 10 \mathrm{BKSU}+\mathrm{k} 11 \mathrm{BKI}+\mathrm{U} 11 \ldots \ldots . .(17)$


$\mathrm{KSMNP}=10+11 \mathrm{BKP}+12 \mathrm{BKAN}$

$+13 \mathrm{BKPBB}+14 \mathrm{BKBN}+15 \mathrm{BKL}+16$

$\mathrm{BKPL}+\mathrm{U} 12$

Dimana :

PNUT : Penerimaan usahatani (Rp/tahun)

BB : Biaya benih (Rp/tahun)

BP : Biaya pupuk (Rp/tahun)

BPS : Biaya pestisida (Rptahun)

BTKUT: Biaya tenaga kerja usahatani (Rp/tahun)

BUT : Biaya usahatani (Rp/tahun)

PNDUT: Pendapatan usahatani (Rp/tahun)

TAWUT: Total alokasi waktu usahatani (jam/tahun)

TAWNUT: Total alokasi waktu non usahatani (jam/tahun)

AKK : Angkatan kerja dalam keluarga (orang)

PNDK : Pendidikan kepala keluarga (Dummy)

LLN : luas lahan (Meter persegi)

UMR : Umur kepala keluarga (Tahun)

TKDG : Tenaga kerja dagang (orang)

TKJS : Tenaga kerja jasa (orang)

TKRMT: Tenaga kerja remittance (orang)

TKBR : Tenaga kerja buruh (orang)

TKNUT: Tenaga kerja non usahatani (orang)

PNDDG: Pendapatan dagang (Rp/tahun)

PNDJS : Pendapatan jasa (Rp/tahun)

PNDRMT: Pendapatan remittance

(Rp/tahun)

PNDBR: Pendapatan buruh (Rp/tahun)

PNDNUT: Pendapatan non usahatani (Rp/tahun)
PNDTOT: Pendapatan total rumah tangga petani (Rp/tahun)

KSM : Konsumsi (Rp/bulan)

KSMP : Konsumsi pangan (Rp/bulan)

KSMNP: Konsumsi non pangan (Rp/bulan)

BKB : Biaya konsumsi beras (Rp/bulan)

BKJ : Biaya konsumsi jagung

(Rp/bulan)

BKSG : Biaya konsumsi singkong (Rp/bulan)

BKS : Biaya konsumsi sayur (Rp/bulan)

BKD : Biaya konsumsi daging

(Rp/bulan)

BKG : Biaya konsumsi gula (Rp/bulan)

BKA : Biaya konsumsi ayam (Rp/bulan)

BKR : Biaya konsumsi rokok (Rp/bulan)

BKT : Biaya konsumsi telur (Rp/bulan)

BKSU : Biaya konsumsi susu (Rp/bulan)

BKI : Biaya konsumsi ikan (Rp/bulan)

BKP : Biaya konsumsi pendidikan (Rp/bulan)

BKAN : Biaya konsumsi arisan (Rp/bulan)

BKPBB: Biaya konsumsi PBB (Rp/bulan)

$\mathrm{BKBN}$ : Biaya konsumsi bensin (Rp/bulan)

BKL : Biaya konsumsi listrik (Rp/bulan)

BKPL : Biaya konsumsi pulsa (Rp/bulan)

a0, b0, c0, d0, e0, f0, g0, h0, i0, j0, k0, 10 : Intersep

a1-a4, b1-b6, c1-c5, d1-d5, e1-e5, f1-f5, g1g5, h1-h6, i1-i6, j1-j6, k1-k6, 11-16: Koefisien regresi (nilai yang diharapkan > 0)

U1, U2, U3, U4, U5, U6, U7, U8, U9, U10, U11, U12: Disturbance term 


\section{Analisis Angka Gini Rasio}

Analisis angka gini dipakai sebagai indikator yang menunjukkan distribusi pendapatan suatu populasi yang nilainya 0 -

1, dengan ketentuan sebagai berikut :

- Nilai 1 berarti ketimpangan pendapatan tidak merata sempurna

- Nilai 0 berarti ketimpangan pendapatan merata sempurna

Secara sistematis, Angka Gini Rasio dirumuskan sebagai berikut:

$$
\mathrm{AG}=1-\sum_{i=1}^{N} A_{i} \frac{\left(Q_{i}+\left(Q_{i-1}\right)\right)}{10.000}
$$

Dimana:

$A_{i}=$ Prosentase rumah tangga pada kelas pendapatan ke-i

$\mathrm{Q}_{\mathrm{i}}=$ Prosentase kumulatif pendapatan sampai pendapatan ke-i

$\mathrm{Q}_{\mathrm{i}-1} \quad=$ Prosentase kumulatif pendapatan sampai kelas ke- (i-1)

$\mathrm{N}$ = Banyaknya kelas

1 dan 10.000 adalah Konstanta

\section{HASIL DAN PEMBAHASAN}

\section{Tingkat Diversifikasi Pendapatan}

Tingkat diversifikasi pendapatan merupakan seberapa besar keragaman aktivitas usaha yang dilakukan oleh suatu rumah tangga untuk memperoleh pendapatan baru. Dalam penelitian ini aktivitas usaha dikelompokkan menjadi lima pekerjaan mulai dari aktivitas menjadi petani, buruh, termasuk buruh tani, buruh pabrik, dan buruh bangunan. Selanjutnya adalah aktivitas di bidang jasa, terdiri dari menjadi perangkat desa, guru mengaji, gravir (pembuat nama di piring atau sendok) dan penjahit. Aktivitas di bidang dagang dan aktivitas menjadi tenaga kerja diluar negeri atau diluar daerah yang dikelompokkan di dalam remittance.

Aktivitas usaha menjadi petani memiliki prosentase terbesar yaitu $40,79 \%$ dan urutan kedua adalah aktivitas usaha menjadi buruh dengan prosentase sebesar $31,58 \%$. Selanjutnya adalah aktivitas dagang yaitu $11,84 \%$, aktivitas jasa $10,52 \%$, dan remittance $5,27 \%$. Hal ini menunjukkan bahwa pekerjaan menjadi petani masih menjadi aktivitas usaha yang dominan di daerah pedesaan khususnya di Dusun Patuk Baran ini. Jumlah prosentase ragam pendapatan yang ada di Dusun Patuk Baran dapat dilihat pada tabel berikut ini.

Tabel 1. Jumlah Prosentase Aktivitas Usaha di Dusun Patuk Baran

\begin{tabular}{|c|c|c|}
\hline Keterangan & Jumlah (orang) & Prosentase (\%) \\
\hline Petani & 31 & $40,79 \%$ \\
\hline Buruh & 24 & $31,58 \%$ \\
\hline Jasa & 8 & $10,52 \%$ \\
\hline Dagang & 9 & $11,84 \%$ \\
\hline Remittance & 4 & $5,27 \%$ \\
\hline
\end{tabular}

Sumber: Data primer diolah, 2011 
Berdasarkan hasil rata-rata statistik deskriptif didapatkan rata-rata untuk pendapatan usahatani yaitu sebesar $\mathrm{Rp}$ 7.010.566 per tahun jauh lebih kecil dibandingkan rata-rata pada pendapatan non usahatani yaitu sebesar Rp 13.116.220 per tahun. Walaupun usahatani sebagian besar merupakan pekerjaan pokok rumah tangga petani tetapi pendapatan yang mereka perolah lebih besar pada pekerjaan sampingan mereka yaitu pada aktivitas usaha diluar usahatani. Hal ini disebabkan, perolehan pendapatan dari kegiatan usahatani yang tidak stabil dan tergantung nilai tukar petani, kegagalan dalam panen yang tidak terduga, petani yang tidak bisa menjual produknya langsung ke konsumen, orientasi petani yang masih menyisakan sebagian produknya untuk konsumsi sendiri.
Faktor-faktor yang Mempengaruhi Diversifikasi Pendapatan Dilihat dari

\section{Alokasi Kerja di Sektor Pertanian}

Berdasarkan analisis metode 2SLS, menunjukkan bahwa koefisien dugaan biaya tenaga kerja usahatani berhubungan positif dengan total alokasi waktu usahatani, total alokasi waktu non usahatani, angkatan kerja dalam keluarga, luas lahan, dan umur kepala keluarga serta berhubungan negatif dengan pendidikan kepala keluarga. Hal ini menggambarkan peningkatan total alokasi waktu usahatani, total alokasi waktu non usahatani, angkatan kerja dalam keluarga, luas lahan, dan umur akan meningkatkan biaya tenaga kerja usahatani. Sedangkan peningkatan pendidikan akan menurunkan biaya tenaga kerja usahatani.

Tabel 2. Hasil Estimasi Parameter Biaya Tenaga Kerja Usahatani

\begin{tabular}{|l|l|l|l|l|}
\hline \multicolumn{1}{|c|}{ Peubah } & $\begin{array}{l}\text { Parameter } \\
\text { Dugaan }\end{array}$ & $\begin{array}{l}\text { T } \\
\text { hitung }\end{array}$ & Probabilitas & $\begin{array}{l}\text { Taraf } \\
\text { Nyata }\end{array}$ \\
\hline Biaya tenaga kerja usahatani (BTKUT) & & & & \\
\hline Intersep & 256112 & 0.417 & 0.6816 & $\alpha=0.25$ \\
\hline Total alokasi waktu usahatani (TAWUT) & 65.233190 & 0.392 & 0.7000 & $\alpha=0.25$ \\
\hline Total alokasi waktu non usahatani (TAWNUT) & 32.763538 & 0.456 & 0.6535 & $\alpha=0.25$ \\
\hline Angkatan kerja dalam keluarga (AKK) & 47445 & 0.344 & 0.7351 & $\alpha=0.25$ \\
\hline Pendidikan kepala keluarga (PNDK) & -572100 & -1.552 & $0.1380 * * * *$ & $\alpha=0.25$ \\
\hline Luas lahan (LLN) & 28.544857 & 3.826 & $0.0012 *$ & $\alpha=0.01$ \\
\hline Umur kepala keluarga (UMR) & 5351.760964 & 0.927 & $0.3661 * * * *$ & $\alpha=0.25$ \\
\hline \multicolumn{2}{|c|}{$\mathrm{R}^{2}=0.5626 ;$ F Hitung $=3.858$, Probabilitas } \\
\hline
\end{tabular}

Sumber: Data primer diolah, 2011.

Keterangan: * nyata pada taraf $\alpha=0,01$ $* * * *$ nyata pada taraf $\alpha=0,25$

Berdasarkan tabel 2 nilai koefisien determinasi pada persamaan penerimaan usahatani sebesar 0,5626 Ini menunjukkan bahwa persamaan biaya tenaga kerja usahatani dapat dijelaskan oleh variabel-variabel yang terdapat dalam model tersebut sebesar 56,26 persen dan sisanya 43,74 persen dijelaskan oleh 
variabel lain yang terdapat di luar model.

Hasil analisis menunjukkan nilai

hitung sebesar 3.858 di mana nilai tersebut lebih besar dari F-tabel $(4,01)$ pada taraf kepercayaan $\alpha=0,01$. Hal tersebut menunjukkan keseluruhan peubah independen yang dimasukkan dalam model secara bersama-sama berpengaruh terhadap biaya tenaga kerja usahatani.

Berdasarkan uji t bahwa faktorfaktor yang mempengaruhi biaya tenaga kerja usahatani adalah :

1. Pendidikan kepala keluarga (PNDK) Berdasarkan uji t, diperoleh $\mathrm{t}$ hitung sebesar -1,552 pada taraf kepercayaan $\alpha=0.25$, dimana nilai tersebut lebih besar dari t tabel $(0,688)$, yang berarti bahwa pendidikan kepala keluarga berpengaruh nyata terhadap biaya tenaga kerja usahatani. Dengan demikian perubahan pendidikan kepala keluarga akan menyebabkan perubahan pada biaya tenaga kerja usahatani.

2. Luas lahan (LLN)

Berdasarkan uji t, diperoleh $\mathrm{t}$ hitung sebesar 3,826 pada taraf kepercayaan $\alpha=0.01$, dimana nilai tersebut lebih besar dari t tabel $(2,552)$, yang berarti bahwa luas lahan berpengaruh nyata terhadap biaya tenaga kerja usahatani. Dengan demikian perubahan luas lahan akan menyebabkan perubahan pada biaya tenaga kerja usahatani.

3. Umur kepala keluarga (UMR)
Berdasarkan uji t, diperoleh $\mathrm{t}$ hitung sebesar 0,927 pada taraf kepercayaan $\alpha=0,25$, dimana nilai tersebut lebih besar dari t tabel $(0,688)$, yang berarti bahwa umur kepala keluarga berpengaruh nyata terhadap biaya tenaga kerja usahatani. Dengan demikian perubahan umur kepala keluarga akan menyebabkan perubahan pada biaya tenaga kerja usahatani.

Dari hasil analisis diatas dapat kita simpulkan bahwa faktor-faktor yang mempengaruhi diversifikasi pendapatan dilihat dari alokasi kerja di sektor pertanian adalah pendidikan kepala keluarga, luas lahan yang dimiliki serta umur kepala keluarga. Kepemilikan luas lahan sangat mempengaruhi rumah tangga petani untuk melakukan diversifikasi pendapatan, dari hasil penelitian sebagian besar petani yang memiliki lahan luas yaitu diatas 1 hektar lebih memilih tidak melakukan kegiatan usaha lain diluar dari usahatani. Selain itu, usia-usia yang lebih banyak bekerja disektor pertanian adalah usia yang sudah tidak produktif lagi, sehingga menyebabkan mereka enggan untuk bekerja di kegiatan usaha yang lain karena faktor kesehatan yang semakin menurun.

Faktor-Faktor yang Mempengaruhi Peluang Kerja di Non Pertanian

Berdasarkan nilai koefisien determinasi pada persamaan tenaga kerja dagang sebesar 0,2540. Ini menunjukkan 
bahwa persamaan tenaga kerja dagang dapat dijelaskan oleh variabel-variabel yang terdapat dalam model tersebut sebesar 25,40 persen dan sisanya sebesar 74,60 persen dijelaskan oleh variabel lain yang terdapat di luar model. Pada persamaan tenaga kerja jasa diperoleh koefisien determinasi sebesar 0,3736. Hal tersebut menunjukkan bahwa 37,36 persen peubah nilai tenaga kerja jasa dapat dijelaskan oleh peubah bebas yang dimasukkan dalam model, sedangkan sisanya sebesar 62,64 persen dijelaskan oleh peubah lain yang tidak dimasukkan dalam model. Koefisien determinasi pada persamaan tenaga kerja remittance sebesar 0,2619. Hal tersebut menunjukkan bahwa 26,19 persen peubah nilai tenaga kerja remittance dapat dijelaskan oleh peubah bebas yang dimasukkan dalam model, sedangkan sisanya sebesar 73,81 persen dijelaskan oleh peubah lain yang tidak dimasukkan dalam model. Sedangkan koefisien determinasi pada persamaan tenaga kerja buruh diperoleh sebesar 0.5144. Ini menunjukkan bahwa persamaan tenaga kerja buruh dapat dijelaskan oleh variabel-variabel yang terdapat dalam model tersebut sebesar 51,44 persen dan sisanya sebesar 48,56 persen dijelaskan oleh variabel lain yang terdapat di luar model.

Berdasarkan uji t bahwa faktorfaktor yang mempengaruhi tenaga kerja dagang adalah total alokasi waktu usahatani dan angkatan kerja dalam keluarga. Apabila total alokasi waktu usahatani yang dilakukan rumah tangga petani lebih sedikit pasti mereka akan lebih banyak mencurahkan waktunya untuk kegiatan diluar usahatani. Untuk tenaga kerja jasa adalah luas lahan dan umur kepala keluarga. kepemilikan lahan yang relatif sempit dan umur yang masih dalam usia produktif tentu saja rumah tangga petani akan memilih melakukan diversifikasi pendapatan pada kegiatan diluar usahatani untuk mencukupi kebutuhan hidupnya.

Pada tenaga kerja remittance adalah pendidikan kepala keluarga, hal ini dikarenakan untuk menjadi tenaga kerja luar negeri atau bekerja diluar daerah tentu saja harus memiliki pengetahuan dan keterampilan khusus. Oleh karena itu, tingkat pendidikan sangat dibutuhkan pada kegiatan usaha remittance ini. Sedangkan pada tenaga kerja buruh adalah angkatan kerja dalam keluarga, pendidikan kepala keluarga, luas lahan dan konsumsi. Luas kepemilikan lahan yang sempit serta tingkat pendidikan yang rendah menyebabkan peluang kerja disektor non usahatani pada rumah tangga petani hanya terbatas pada kegiatan untuk menjadi buruh kasar.

Berdasarkan analisis metode 2SLS, menunjukkan bahwa koefisien dugaan tenaga kerja dagang berhubungan positif dengan angkatan kerja dalam keluarga, pendidikan kepala keluarga, luas lahan, dan umur kepala keluarga serta 
berhubungan negatif dengan total alokasi waktu usahatani dan konsumsi. Koefisien dugaan pada tenaga kerja jasa berhubungan positif dengan pendidikan kepala keluarga dan luas lahan serta berhubungan negatif dengan total alokasi waktu usahatani, angkatan kerja dalam keluarga, umur kepala keluarga, dan konsumsi. Sedangkan koefisien dugaan pada tenaga kerja remittance berhubungan positif dengan total alokasi waktu usahatani, angkatan kerja dalam keluarga, dan umur kepala keluarga serta berhubungan negatif dengan pendidikan kepala keluarga, luas lahan, dan konsumsi. Terakhir adalah koefisien dugaan tenaga kerja buruh berhubungan positif dengan angkatan kerja dalam keluarga, pendidikan kepala keluarga, umur kepala keluarga dan konsumsi serta berhubungan negatif dengan total alokasi waktu usahatani dan luas lahan.

Tabel 3. Hasil Estimasi Parameter Tenaga Kerja Non Usahatani

\begin{tabular}{|c|c|c|c|c|}
\hline Peubah & $\begin{array}{l}\text { Parameter } \\
\text { Dugaan }\end{array}$ & $\begin{array}{l}\text { T } \\
\text { hitung }\end{array}$ & Probobalitas & $\begin{array}{l}\text { Taraf } \\
\text { Nyata }\end{array}$ \\
\hline \multicolumn{5}{|l|}{ Tenaga Kerja Dagang (TKDG) } \\
\hline Intersep & -0.126681 & -0.112 & 0.9123 & $\alpha=0.25$ \\
\hline Total alokasi waktu usahatani (TAWUT) & -0.000313 & -1.293 & $0.2123 * * * *$ & $\alpha=0.25$ \\
\hline Angkatan kerja dalam keluarga (AKK) & 0.316496 & 1.815 & $0.0863 * * *$ & $\alpha=0.10$ \\
\hline Pendidikan kepala keluarga (PNDK) & 0.371600 & 0.565 & 0.5792 & $\alpha=0.25$ \\
\hline Luas lahan (LLN) & 0.000007533 & 0.401 & 0.6932 & $\alpha=0.25$ \\
\hline Umur kepala keluarga (UMR) & 0.004404 & 0.428 & 0.6740 & $\alpha=0.25$ \\
\hline \multirow[t]{2}{*}{ Konsumsi (KSM) } & $-5.147796 \mathrm{E}-8$ & -0.876 & $0.3927 * * * *$ & $\alpha=0.25$ \\
\hline & \multicolumn{4}{|c|}{$\begin{array}{c}\mathrm{R}^{2}=0.2540 ; \text { F Hitung }=1.022, \text { Probabilitas } \\
0.4428\end{array}$} \\
\hline \multicolumn{5}{|l|}{ Tenaga kerja jasa (TKJS) } \\
\hline Intersep & 0.972230 & 1.346 & 0.1951 & $\alpha=0.25$ \\
\hline Total alokasi waktu usahatani (TAWUT) & -0.000103 & -0.667 & 0.5134 & $\alpha=0.25$ \\
\hline Angkatan kerja dalam keluarga (AKK) & -0.017673 & -0.159 & 0.8754 & $\alpha=0.25$ \\
\hline Pendidikan kepala keluarga (PNDK) & 0.077385 & 0.185 & 0.8556 & $\alpha=0.25$ \\
\hline Luas lahan (LLN) & 0.000021234 & 1.774 & $0.0930 * * *$ & $\alpha=0.10$ \\
\hline Umur kepala keluarga (UMR) & -0.013973 & -2.130 & $0.0472 * *$ & $\alpha=0.05$ \\
\hline \multirow[t]{2}{*}{ Konsumsi (KSM) } & $-3.15093 \mathrm{E}-10$ & -0.008 & 0.9934 & $\alpha=0.25$ \\
\hline & \multicolumn{4}{|c|}{$\begin{array}{c}\mathrm{R}^{2}=0.3736 ; \text { F Hitung }=1.789, \text { Probabilitas } \\
0.1581_{* * *}\end{array}$} \\
\hline \multicolumn{5}{|l|}{ Tenaga kerja remittance (TKRMT) } \\
\hline Intersep & 0.799977 & 1.188 & 0.2501 & $\alpha=0.25$ \\
\hline Total alokasi waktu usahatani (TAWUT) & 0.000015891 & 0.110 & 0.9133 & $\alpha=0.25$ \\
\hline Angkatan kerja dalam keluarga (AKK) & 0.085291 & 0.824 & 0.4207 & $\alpha=0.25$ \\
\hline Pendidikan kepala keluarga (PNDK) & -0.864961 & -2.215 & $0.0399 * *$ & $\alpha=0.05$ \\
\hline Luas lahan (LLN) & -0.000003539 & -0.317 & 0.7547 & $\alpha=0.25$ \\
\hline Umur kepala keluarga (UMR) & 0.000508 & 0.083 & 0.9346 & $\alpha=0.25$ \\
\hline \multirow[t]{2}{*}{ Konsumsi (KSM) } & $-9.22603 \mathrm{E}-10$ & -0.026 & 0.9792 & $\alpha=0.25$ \\
\hline & \multicolumn{4}{|c|}{$\begin{array}{c}\mathrm{R}^{2}=0.2619 ; \text { F Hitung }=1.064, \text { Probabilitas } \\
0.4190\end{array}$} \\
\hline \multicolumn{5}{|l|}{ Tenaga kerja buruh (TKBR) } \\
\hline Intersep & -1.606580 & -1.226 & 0.2361 & $\alpha=0.25$ \\
\hline Total alokasi waktu usahatani (TAWUT) & -0.000159 & -0.569 & 0.5761 & $\alpha=0.25$ \\
\hline
\end{tabular}




\begin{tabular}{|l|l|l|l|l|}
\hline Angkatan kerja dalam keluarga (AKK) & 0.721759 & 3.582 & $0.0021^{*}$ & $\alpha=0.01$ \\
\hline Pendidikan kepala keluarga (PNDK) & 1.001725 & 1.318 & $0.2042 * * * *$ & $\alpha=0.25$ \\
\hline Luas lahan (LLN) & -0.000038117 & -1.756 & $0.0962 * * *$ & $\alpha=0.10$ \\
\hline Umur kepala keluarga (UMR) & 0.002403 & 0.202 & 0.8422 & $\alpha=0.25$ \\
\hline Konsumsi (KSM) & $7.9511832 \mathrm{E}-8$ & 1.171 & $0.2570 * * *$ & $\alpha=0.25$ \\
\hline \multicolumn{3}{|c|}{$\mathrm{R}^{2}=0.5144 ;$ F Hitung $=3.179$, Probabilitas } \\
\hline
\end{tabular}

Sumber: Data primer diolah, 2011

Keterangan: * nyata pada taraf $\alpha=0,01$

** nyata pada taraf $\alpha=0,05$

*** nyata pada taraf $\alpha=0,10$

$* * * *$ nyata pada taraf $\alpha=0,25$

Hasil analisis menunjukkan nilai $\mathrm{F}$ hitung untuk tenaga kerja dagang, tenaga kerja jasa, tenaga kerja remittance, dan tenaga kerja buruh, masing-masing sebesar 1,$022 ; 1,789 ; 1,064 ;$ dan 3,179 di mana hanya nilai $\mathrm{F}$ hitung tenaga buruh saja yang lebih besar dari F-tabel $(2,66)$ pada taraf kepercayaan $\alpha=0,05$. Hal tersebut menunjukkan keseluruhan peubah independen yang dimasukkan dalam model secara bersama-sama berpengaruh terhadap tenaga tenaga kerja buruh. Sedangkan keseluruhan peubah independen yang dimasukkan dalam model secara bersamasama tidak berpengaruh terhadap tenaga kerja dagang, tenaga kerja jasa, dan tenaga kerja remittance. Hal ini dikarenakan nilai F hitungnya lebih kecil dari F-tabel.

\section{Simulasi I Peningkatan Pendidikan}

\section{Kepala Keluargasebesar $10 \%$}

Pendidikan merupakan salah satu faktor yang mempengaruhi seseorang untuk melakukan diversifikasi pendapatan. Peningkatan pendidikan pada kepala keluarga rumah tangga petani khususnya terhadap peningkatan keahlian atau keterampilan, diharapkan agar kepala keluarga rumah tangga petani mampu melakukan berbagai variasi pekerjaan dalam memperoleh pendapatan tidak hanya menggantungkan dari kegiatan bertani saja. Tetapi mereka dapat mengaplikasikan keahliannya pada bidang-bidang yang lain. Berikut pada tabel dibawah ini, dapat kita lihat aspekaspek yang terpengaruh dalam peningkatan pendidikan kepala keluarga rumah tangga petani. 
Tabel 4. Dampak Peningkatan Pendidikan Kepala Keluarga sebesar $10 \%$

\begin{tabular}{|l|l|l|l|}
\hline Aspek yang terpengaruh & $\begin{array}{l}\text { Nilai simulasi } \\
\text { dasar }\end{array}$ & $\begin{array}{l}\text { Nilai simulasi } \\
\text { kebijakan }\end{array}$ & $\begin{array}{l}\text { Perubahan } \\
(\%)\end{array}$ \\
\hline PNUT (Penerimaan Usahatani) & 8112284 & 7305924.11 & -9.94 \\
\hline BTKUT (Biaya Tenaga Kerja Usahatani) & 413548 & 358626.12 & -13.28 \\
\hline TKDG (Tenaga Kerja Dagang) & 0.3200 & 0.3821 & 19.40 \\
\hline TKJS (Tenaga Kerja Jasa) & 0.2400 & 0.2475 & 3.12 \\
\hline TKRMT (Tenaga Kerja Remittance) & 0.1600 & 0.0774 & -51.62 \\
\hline TKBR (Tenaga Kerja Buruh) & 0.8400 & 0.8970 & 6.78 \\
\hline PNDDG (Pendapatan Dagang) & 1579200 & 1740111 & 10.19 \\
\hline PNDJS (pendapatan Jasa) & 2889600 & 3320581.74 & 14.91 \\
\hline PNDRMT (Pendapatan Remittance) & 1562000 & 1234091.71 & -20.99 \\
\hline PNDBR (Pendapatan Buruh) & 2633820 & 2751445.99 & 4.46 \\
\hline
\end{tabular}

Sumber: Data primer diolah, 2011.

Berdasarkan tabel diatas peningkatan pendidikan sebesar $10 \%$ meningkatkan tenaga kerja dagang sebesar $19,4 \%$, tenaga kerja jasa sebesar $3,12 \%$, tenaga kerja buruh sebesar $6,78 \%$, pendapatan dagang sebesar 10,19\%, pendapatan jasa sebesar $14,91 \%$, dan pendapatan buruh sebesar $4,46 \%$. Hasil dari kebijakan tersebut juga menurunkan penerimaan usahatani sebesar $9,94 \%$, biaya tenaga kerja usahatani sebesar $13,28 \%$, tenaga remittance sebesar $51,62 \%$, dan pendapatan remittance sebesar 20,99\%. Hal ini menunjukkan bahwa dengan adanya peningkatan pendidikan kepada kepala keluarga rumah tangga petani, berdampak terhadap peningkatan pekerjaan diluar non usahatani, sehingga perolehan pendapatan tidak hanya berasal dari satu sumber saja, yang tentunnya akan berimplikasi terhadap peningkatan kesejahteraan pada rumah tangga petani.
Simulasi II Peningkatan Pendapatan Non Usahatani sebesar $20 \%$

Berdasarkan hasil simulasi dengan meningkatkan pendapatan non usahatani sebesar 20\%, berdampak langsung pada penurunan penerimaan usahatani sebesar $5,99 \%$, biaya tenaga kerja usahatani $6,77 \%$, tenaga kerja buruh sebesar $4,65 \%$, pendapatan remittance sebesar $8,86 \%$, dan pendapatan buruh 2,14\% .

Selain itu, kebijakan tersebut meningkatkan tenaga kerja dagang sebesar $8,26 \%$, tenaga kerja remittance sebesar $0,25 \%$, pendapatan dagang sebesar 5,17\%, dan pendapatan jasa sebesar 3,19\%. Kebijakan tersebut diharapkan dapat menciptakan kesempatan kerja baru atau membuka peluang kerja pada kegiatan non usahatani di daerah pedesaan. Berikut aspek-aspek yang terpengaruh dalam peningkatan pendapatan non usahatani. 
Tabel 5. Peningkatan Pendapatan Non Usahatani sebesar $20 \%$

\begin{tabular}{|l|l|l|l|}
\hline \multicolumn{1}{|c|}{ Aspek yang terpengaruh } & $\begin{array}{l}\text { Nilai } \\
\text { simulasi } \\
\text { dasar }\end{array}$ & $\begin{array}{l}\text { Nilai simulasi } \\
\text { kebijakan }\end{array}$ & $\begin{array}{l}\text { Perubahan } \\
(\%)\end{array}$ \\
\hline PNUT (Penerimaan Usahatani) & 8112284 & 8112279.14 & -5.99 \\
\hline $\begin{array}{l}\text { BTKUT (Biaya Tenaga Kerja } \\
\text { Usahatani) }\end{array}$ & 413548 & 413547.72 & -6.77 \\
\hline TKDG (Tenaga Kerja Dagang) & 0.3200 & 0.34644 & 8.26 \\
\hline TKJS (Tenaga Kerja Jasa) & 0.2400 & 0.2400 & 0.00 \\
\hline $\begin{array}{l}\text { TKRMT (Tenaga Kerja } \\
\text { Remittance) }\end{array}$ & 0.1600 & 0.1604 & 0.25 \\
\hline TKBR (Tenaga Kerja Buruh) & 0.8400 & 0.8009 & -4.65 \\
\hline PNDDG (Pendapatan Dagang) & 1579200 & 1660904.95 & 5.17 \\
\hline PNDJS (pendapatan Jasa) & 2889600 & 2981670.92 & 3.19 \\
\hline PNDRMT (Pendapatan Remittance) & 1562000 & 1423566.33 & -8.86 \\
\hline PNDBR (Pendapatan Buruh) & 2633820 & 2577324.36 & -2.14 \\
\hline
\end{tabular}

Sumber: Data primer diolah, 2011.

\section{Simulasi III Peningkatan Total Alokasi}

\section{Waktu Non Usahatani sebesar $20 \%$}

Peningkatan total alokasi waktu non usahatani berdampak langsung terhadap peningkatan penerimaan usahatani sebesar $2,57 \%$, biaya tenaga kerja usahatani sebesar 3,44\%, tenaga kerja dagang sebesar $8,26 \%$, tenaga kerja remittance sebesar $0,25 \%$, pendapatan dagang sebesar $5,17 \%$, dan pendapatan jasa sebesar 3,19\%. Kebijakan ini juga menurunkan tenaga kerja buruh sebesar $4,65 \%$, pendapatan remittance sebesar $8,86 \%$, dan pendapatan buruh sebesar $2,14 \%$. Aspek-aspek yang terpengaruh pada peningkatan total alokasi waktu non usahatani dapat dilihat pada tabel dibawah ini.

Tabel 6. Peningkatan Total Alokasi Waktu Non Usahatani sebesar $20 \%$

\begin{tabular}{|l|l|l|c|}
\hline Aspek yang terpengaruh & $\begin{array}{l}\text { Nilai simulasi } \\
\text { dasar }\end{array}$ & $\begin{array}{l}\text { Nilai simulasi } \\
\text { kebijakan }\end{array}$ & $\begin{array}{r}\text { Perubahan } \\
(\%)\end{array}$ \\
\hline PNUT (Penerimaan Usahatani) & 8112284 & 8321212.48 & 2.57 \\
\hline BTKUT (Biaya Tenaga Kerja Usahatani) & 413548 & 427778.37 & 3.44 \\
\hline TKDG (Tenaga Kerja Dagang) & 0.3200 & 0.34644 & 8.26 \\
\hline TKJS (Tenaga Kerja Jasa) & 0.2400 & 0.2400 & 0.00 \\
\hline TKRMT (Tenaga Kerja Remittance) & 0.1600 & 0.1604 & 0.25 \\
\hline TKBR (Tenaga Kerja Buruh) & 0.8400 & 0.8009 & -4.65 \\
\hline PNDDG (Pendapatan Dagang) & 1579200 & 1660904.95 & 5.17 \\
\hline PNDJS (pendapatan Jasa) & 2889600 & 2981670.92 & 3.19 \\
\hline PNDRMT (Pendapatan Remittance) & 1562000 & 1423566.33 & -8.86 \\
\hline PNDBR (Pendapatan Buruh) & 2633820 & 2577324.36 & -2.14 \\
\hline
\end{tabular}

Sumber: Data primer diolah, 2011. 
Peningkatan total alokasi waktu non usahatani, diharapkan dapat menambah waktu atau durasi jam kerja rumah tangga petani daripada digunakan untuk waktu bersantai. Hal ini dikarenakan, kebanyakan waktu petani setelah melakukan kegiatan usahataninya lebih banyak dihabiskan untuk bersantai dirumah dengan tidak menghasilkan pendapatan apapun. Jadi dengan adanya peningkatan total alokasi waktu non usahatani, petani tidak menghabiskan waktunya dengan sia-sia dan dapat memperoleh tambahan pendapatan dari pengalokasian waktu kerja yang lebih lama.

\section{Simulasi IV Penurunan Total Alokasi}

\section{Waktu Usahatani $15 \%$}

Perkembangan teknologi dan pembangunan pedesaan yang ada saat ini, menyebabkan banyaknya kalangan usia muda lebih memilih bekerja diluar usahatani. Hal ini menyebabkan berkurangnya usia-usia produktif yang bekerja sebagai petani, sehingga produktivitas pertanianpun semakin menurun. Faktor-faktor yang menyebabkan kondisi tersebut antara lain adalah, faktor lingkungan sekitar, faktor gengsi, ataupun kondisi geografis yang ada di daerah tersebut, dalam hal ini semakin banyaknya alih fungsi lahan pertanian. Jika kebijakan ini masih dilakukan, sehingga mempengaruhi penurunan total alokasi waktu usahatani sebesar 15\%, maka pengaruhnya dapat dilihat pada tabel 7 .

Berdasarkan hasil simulasi diatas penurunan total alokasi waktu usahatani sebesar $15 \%$ berdampak pada penurunan penerimaan usahatani sebesar $2,83 \%$, biaya tenaga kerja usahatani sebesar $3,78 \%$, tenaga kerja dagang sebesar $3,9 \%$, tenaga kerja remittance sebesar $1,23 \%$, dan pendapatan remittance sebesar 3,37\%. Kebijakan tersebut, meningkatkan tenaga kerja jasa sebesar $9,22 \%$, pendapatan dagang sebesar $12,5 \%$, pendapatan jasa sebesar $16,24 \%$, pendapatan buruh sebesar $6,39 \%$.

Tabel 7. Penurunan Total Alokasi Waktu Usahatani $15 \%$

\begin{tabular}{|l|l|l|r|}
\hline \multicolumn{1}{|c|}{ Aspek yang terpengaruh } & $\begin{array}{l}\text { Nilai } \\
\text { simulasi } \\
\text { dasar }\end{array}$ & $\begin{array}{l}\text { Nilai simulasi } \\
\text { kebijakan }\end{array}$ & $\begin{array}{r}\text { Perubahan } \\
(\%)\end{array}$ \\
\hline PNUT (Penerimaan Usahatani) & 8112284 & 8342012.496 & 3.83 \\
\hline BTKUT (Biaya Tenaga Kerja Usahatani) & 413548 & 429195.0712 & 3.90 \\
\hline TKDG (Tenaga Kerja Dagang) & 0.3200 & 0.3324864 & -9.22 \\
\hline TKJS (Tenaga Kerja Jasa) & 0.2400 & 0.2178676 & 1.23 \\
\hline TKRMT (Tenaga Kerja Remittance) & 0.1600 & 0.1619736 & -16.50 \\
\hline TKBR (Tenaga Kerja Buruh) & 0.8400 & 0.7013696 & \\
\hline
\end{tabular}




\begin{tabular}{|l|l|l|r|}
\hline PNDDG (Pendapatan Dagang) & 1579200 & 1381766.49 & -12.50 \\
\hline PNDJS (pendapatan Jasa) & 2889600 & 2420396.151 & -16.24 \\
\hline PNDRMT (Pendapatan Remittance) & 1562000 & 1614718.98 & 3.37 \\
\hline PNDBR (Pendapatan Buruh) & 2633820 & 2465374.616 & -6.39 \\
\hline
\end{tabular}

Sumber: Data primer diolah, 2011.

Distribusi Pendapatan Rumah Tangga Petani

Distribusi pendapatan rumah tangga di Dusun Patuk Baran ini dikelompokkan atas rumah tangga berpenghasilan terendah, rendah, tinggi dan tertinggi. Rata-rata pendapatan terendah yang ada di dusun Patuk Baran adalah Rp 2.173.485 per tahun dan pendapatan tertinggi adalah $\mathrm{Rp} 37.860 .642$ per tahunnya.

Untuk mengetahui distribusi pendapatan rumah tangga diantara petani merata atau tidak, maka perlu dihitung dengan menggunakan Indeks Gini (Rasio Gini). Indeks gini harus terletak antara 0 dan 1.Dari hasil analisis diketahui bahwa distribusi pendapatan rumah tangga petani adalah merata. Hal ini dapat dilihat dari nilai indeks gini yang diperoleh sebesar 0,4079 yang masih jauh dari satu.

Selain menggunakan indeks gini, dalam penelitian ini untuk mengukur merata atau tidaknya distribusi pendapatan rumah tangga juga dianalisis menggunakan kurva Lorenz. Makin cembung kurva Lorenz dengan garis $45^{\circ}$ makin kurang merata distribusi pendapatan rumah tangga di suatu wilayah. Sedangkan kurva Lorenz yang dekat dengan garis netral tersebut makin baik distribusi pendapatan rumah tangga di wilayah tersebut. Kurva Lorenz dibuat dengan menggunakan indeks Gini dengan menghitung nilai kumulatif kecil dari distribusi pendapatan tersebut. Berikut adalah gambar dari kurva Lorenz.

Berdasarkan gambar kurva Lorenz dapat kita ketahui bahwa distribusi pendapatan rumah tangga di Dusun Patuk Baran merata. Hal ini dapat dilihat dari kurva Lorenz yang dekat dengan garis $45^{\circ}$ dan tidak terlalu cembung. Dari hasil perhitungan ini dapat kita simpulkan bahwa luas lahan tidak mempengaruhi distribusi pendapatan yang ada di Dusun Patuk Baran ini. Hal ini dikarenakan pendapatan dari rumah tangga petani tidak hanya diperoleh dari pendapatan usahatani saja, tetapi juga diperoleh dari pendapatan non usahatani. Dengan demikian, walaupun rumah tangga petani yang ada di Dusun Patuk Baran memiliki luas lahan pertanian yang sempit tetapi apabila pendapatan dalam kegiatan non usahataninya lebih besar, tidak menyebabkan ketimpangan pendapatan yang terlalu besar dengan petani yang memiliki lahan luas. 


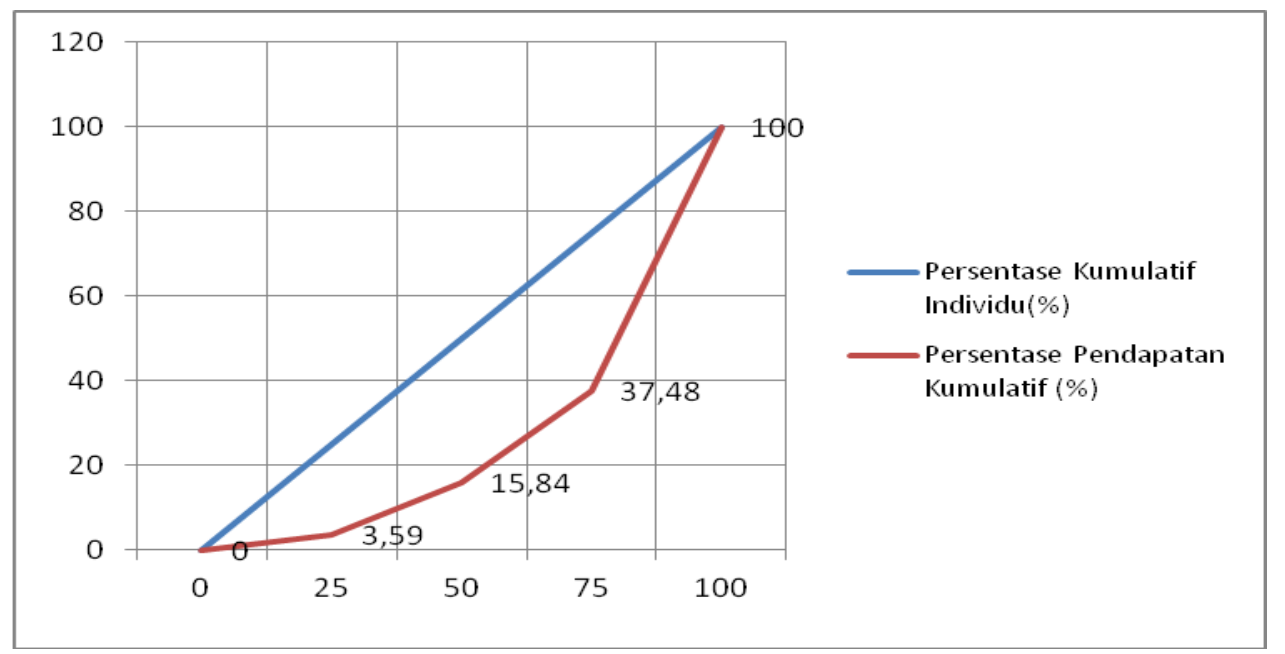

Gambar 1. Kurva Lorenz

\section{KESIMPULAN}

Berdasarkan hasil analisis dan pembahasan dalam uraian sebelumnya, dapat disimpulkan beberapa hal sebagai berikut:

1. Rata-rata pendapatan rumah tangga petani di Dusun Patuk Baran yang berasal dari kegiatan non usahatani jauh lebih tinggi dibandingkan dari kegiatan usahatani, yaitu sebesar Rp 7.010.566 untuk rata-rata pendapatan usahatani per tahun dan Rp 13.116.220 untuk rata-rata pendapatan non usahatani per tahun.

2. Faktor-faktor yang berpengaruh nyata terhadap diversifikasi pendapatan dilihat dari alokasi kerja di sektor pertanian adalah pendidikan kepala keluarga, luas lahan dan umur kepala keluarga.

3. Faktor-faktor yang mempengaruhi peluang kerja di non pertanian, dari kegiatan kerja bidang perdagangan adalah total alokasi waktu usahatani dan angkatan kerja dalam keluarga. Untuk kegiatan kerja bidang jasa adalah luas lahan dan umur kepala keluarga.

Sedangkan pada kegiatan kerja remittance adalah pendidikan kepala keluarga dan pada kegiatan kerja bidang buruh adalah angkatan kerja dalam keluarga, pendidikan kepala keluarga, luas lahan dan konsumsi.

4. Berdasarkan nilai indeks gini sebesar 0,4079 yang masih jauh dari satu dan kurva Lorenz yang dekat dengan garis $45^{\circ}$ dan tidak terlalu cembung, maka distribusi pendapatan yang ada di Dusun Patuk Baran merata, sehingga tidak ada hubungan antara distribusi pendapatan dengan luas lahan.

5. Dampak peningkatan pendidikan kepala keluarga sebesar 10\%, menyebabkan peningkatan pada pendapatan non usahatani, yaitu pendapatan dagang, jasa, dan buruh serta menurunkan penerimaan usahatani. Peningkatan pendapatan non usahatani sebesar $20 \%$ berdampak pada peningkatan 
pendapatan dagang dan jasa, kebijakan ini bertujuan untuk meningkatkan jumlah penyerapan tenaga kerja atau membuka kesempatan kerja baru di pedesaan. Sedangkan dampak dari peningkatan total alokasi waktu non usahatani menyebabkan pendapatan disektor non pertanian meningkat, sehingga petani dalam pengalokasian waktunya tidak digunakan untuk kegiatan yang sia-sia. Terakhir adalah dampak dari penurunan total waktu usahatani menyebabkan penerimaan usahatani menurun. Hal ini disebabkan banyaknya usia-usia muda atau produktif yang enggan bergelut dalam bidang pertanian.

\section{DAFTAR PUSTAKA}

Aart, Schrevel. 1989. Akses Tanah Sebagai Indikator Pendapatan Rumah Tangga Pedesaan. Prisma no. 4 LP3ES, Jakarta.

Badan Perencanaan Pembangunan Nasional. 2002. Studi Analisis Kemiskinan Tahun 2001 (Draft). Bappenas. Jakarta.

Badan Pusat Statistik Kabupaten Kutai Kartanegara. 2006. Indikator Sosial Ekonomi Kabupaten Kutai Kartanegara.

Barret, C.B. dan T. Reardon. 2000. Asset, Activity, and Income Diversification

\author{
Among African Agriculturalist: \\ Somer Practical Issues. Project \\ report to USAID BASIS CRSP. \\ http://www.les.wisc.edu/Ltc/Live/bas \\ glo0003a.pdt.
}

Barro, R. J. 2000. 'Inequality and Growth in a Panel of Countries', Journal of Economic Growth, Vol. 5, No. 1.

Bellante dan Mark Jackson. 1990. Ekonomi Ketenagakerjaan. BPFE UI. Jakarta.

Blejer, M. I. and I. Guerrero. 1990. 'The Impact of Macroeconomic Policies on Income Distribution: An Empirical Study of Philippines'. Review of Economics and Statistics, Vol. 72 .

Boediono. 1982 Ekonomi Mikro. BPFE. Yogyakarta.

Bourgignon, F. and C. Morrisson. 1998. 'Inequality and Development: The Role of Dualism'. Journal of Development Economics, Vol. 57.

Deininger, K. and L. Squire. 1998. 'New Ways of Looking at Old Issues: Inequality and Growth'. Journal of Development Economics, Vol. 57.

Ellis, F. 1989. Peasant Economics. Farm Households and Agrarian 
Development. Cambridge University Press, Cambridge. New York. New Rochelle, Melbourne and Sydney.

Ersado, Lire. 2003. Income Diversification in Zimbabwe: Welfare Implications From Urban and Rural Areas. FCND Discussion Paper No. 152. IFPRI. W ashington. USA.

Feenberg, D. and J. Poterba . 1993. 'Income Inequality and the Incomes of Very High Income Tax Payers: Evidence from Tax Returns'. Tax Policy and the Economy, Vol. 7.

Gatoet Sroe Hardono dan Handewi P. Saliem. 2002. Diversifikasi Pendapatan Rumah Tangga di Indonesia : Analisis Data Susenas. Laporan Hasil Penelitian, Pusat Analisis Sosial Ekonomi dan Pengembangan Pertanian, Bogor.

Handewi P.S. Rachman, Tri B. Purwantini, dan Yuni Marisa. 2006. Prospek Diversifikasi Usaha Rumah Tangga Dalam Mendukung Ketahanan Pangan dan Penanggulangan Kemiskinan. Laporan Hasil Penelitian, Pusat Analisis Sosial Ekonomi dan Pengembangan Pertanian, Bogor.Agro Ekonomi Volume 24 No. 1, Juli 2006 : 1 - 13

Haryono, Dwi. 2008. Dampak Industrialisasi Pertanian Terhadap
Kinerja Sektor Pertanian dan Kemiskinan Perdesaan: Model CGE Recursive Dynamic. Hasil Disertasi Sekolah Pascasarjana Institut Pertanian Bogor.

Hayami. Y., K. Otsuka. 1992. Beyond the Green Revolution: Agricultural Development Strategy into New Century. In Agricultural Technology : Policy Issues for International Community. Washington DC. USA. The World Bank.

Jhingan, M.L. 2000. Ekonomi Pembangunan dan Perencanaan. PT Raja Grafindo Persada. Jakarta.

Kasryno, F., A.M. Fagi dan E. Pasandaran. 2004. Kebijakan Produksi Padi dan Diversifikasi Pertanian dalam Kasryno et al. (Eds) Ekonomi Padi dan Beras Indonesia (hlm. 73-106). Badan Litbang Pertanian. Jakarta.

Koutsoyiannis, 1977. Teory of Econometrics. The Macmillan Press Ltd. New York.

Lewis, W.A. 1954. Economic Development with Unlimited Supplies of Labor In Chenery and Srinivasan (Editors). Handbook of Development Economics.Science Publisher B.V., Amsterdam. 
Li, H., L. C. Xu and H. Zou. 2000. 'Corruption, Income Distribution, and Growth', Economics and Politics'. Vol. 12, No. 2, pp. 155-82.

Manning, C. 2000. Labourmarket adjustment to indonesia.s economic crisis: context, trend, and implications. Bulletin of Indonesian Economic Studies (BIES) 36(1)105136.

Mitchell, Deborah. 1991. Income Transfers in Ten Welfare States. Avebury. Sidney.

Mocan, H. N. (1999), 'Structural Unemployment, Cyclical Unemployment, and Income Inequality'. Review of Economics and Statistics, Vol. 81, No. 1.

Nicholson, Walter. 2002. Mikroekonomi Intermediate. Jakarta : Penerbit Erlangga.

Pakpahan, A. 1990. Refleksi Diversifikasi dalam Teori Ekonomi dalam Suryana et al.(penyunting) Diversifikasi Pertanian dalam Prospek Mercepat Laju Pembangunan Nasional. Pustaka Sinar Harapan. Jakarta.
Payaman J Simanjuntak, 1985. Pengantar Ekonomi Sumber Daya Manusia. BPFE UI. Jakarta.

Pindyck, R.S. and D.L. Rubinfeld. 1991. Econometric Models and Economic Forecast. Third Edition. McGrawHill Inc, New York.

1998.

Econometric Models and Economic Forecast. Fourth Edition. Irwin McGraw-Hill Inc, Boston.

Pramono Hariadi, Arintoko, dan Icuk Rangga Bawono. 2008. Ketimpangan Distribusi Pendapatan di Kabupaten Banyumas Jawa Tengah. Jurnal Ekonomi Pembangunan : Kajian Ekonomi Negara Berkembang, hal : 61-70.

Rahayu, S., Sondi, K., dan Adang, R. 2000. Analisa Pemerataan Pendapatan Usahaternak Sapi Perah Rakyat (Survey Pada Peternakan Sapi Perah Rakyat di KUD Mitra Yasa Kabupaten Tasikmalaya). Fakultas Peternakan, Universitas Padjadjaran. Sumedang.

Raphael O. Babatunde dan Matin Qaim. 2009. Patterns of income diversification in rural Nigeria: determinants and impacts. Quarterly 
Journal of International Agriculture 48 (2009), No. 4: 305-320.

Siburian, Carlos E. 2009. Analisis Gini Ratio Kota Manado Tahun 2009. Bappeda Kota Manado.

Singarimbun, Masri dan Sofian Effendi. 1989. Metode Penelitian Survei. LP3ES. Jakarta.

Stefan Schwarze and Manfred Zeller. 2005. Income diversification of rural households in Central Sulawesi, Indonesia. Quarterly Journal of International Agriculture 44 (2005), No. 1: 61-73.

Suroso, Agus dkk. 2005. Perhitungan Indeks Rasio Gini Kabupaten Banyumas Tahun 2005. Fakultas Ekonomi. Universitas Jenderal Soedirman.

Susilowati, S.H, Supadi dan Ch. Saleh. 2002. Diversifikasi Sumber Pendapatan Rumah tangga di Pedesaan Jawa Barat. Jurnal Agro Ekonomi, No I (20): 85-109.

Todaro, M.P. 1981. Economic Development in The Third World. 2nd edition. Long Man Inc. New York.
Winardi. 1988. Pengantar Ilmu Ekonomi. Tarsito. Bandung.

Zamrowi, M. Taufik. 2007. Analisis Penyerapan Tenaga Kerja pada Industri Kecil (Studi di Industri Kecil Mebel di Kota Semarang). Laporan Hasil Penelitian, Program Studi Magister Ilmu Ekonomi Dan Studi Pembangunan Universitas

Diponegoro Semarang. 